\title{
The Evaluation of Spent Coffee Grounds as Feedstock for Continuous Hydrothermal Liquefaction
}

\author{
J. von Wielligh, C.J. Schabort, R. Venter and S. Marx
}

\begin{abstract}
This study looks at converting a low-value waste in a continuous hydrothermal liquefaction reactor to a high-value biocrude and biochar product. The feedstock chosen for this study was spent coffee grounds (SCG) as spent coffee grounds is a readily available, low-value biomass that does not compete as a food source. The global coffee consumption was reported to be 8.5 million tons in 2015 and is expected to reach 10.5 million tons in 2020. This makes SCG a significant waste product that can be used for the production of renewable fuels. SCG was gathered from a local coffee shop, mixed with water and placed in a high-temperature, high-pressure environment inside a continuous hydrothermal liquefaction pilot reactor. For the purpose of this study, the reactor was operated at $305^{\circ} \mathrm{C}$ and 90-95 bar where the flow rate was varied between 60-120 L/h. All of the products obtained from the continuous HTL reactor were quantitatively analysed to determine the optimal residence time. The maximum biocrude and biochar yields obtained from the HTL of SCG was $302.7 \mathrm{~g} / \mathrm{kg} \mathrm{SCG}$ and $170.7 \mathrm{~g} / \mathrm{kg} \mathrm{SCG}$ respectively, at a biomass loading of 3 vol.\%. The average higher heating value (HHV) was relatively high at $36.43 \mathrm{MJ} / \mathrm{kg}$ and 30.28 $\mathrm{MJ} / \mathrm{kg}$ for the biocrude and biochar respectively. The biocrude had a low oxidative stability as it consisted mostly of $\mathrm{C}_{16}$ and $\mathrm{C}_{18}$ fatty acids. Analyses on the gas phase indicated that mainly $\mathrm{CO}$ and $\mathrm{CO}_{2}$ were produced during the HTL of SCG.
\end{abstract}

Keywords - Spent coffee grounds, continuous hydrothermal liquefaction

\section{INTRODUCTION}

Liquid fuels comprised $96 \%$ of the global transport sector's energy consumption, with diesel and biodiesel specifically providing $36 \%$ of the total 112.9 exajoules consumed in 2015 [1]. The need for a fuel that contains very little sulphur and nitrogen is very important to minimize the impact that the

C.J. Schabort, Senior Lecturer, School of Chemical and Minerals Engineering, North-West University, Potchefstroom, South Africa

J. von Wielligh, R. Venter and S. Marx, School of Chemical and Minerals Engineering, North-West University, Potchefstroom, South Africa combustion of diesel has on the environment. In 2017 the global carbon emissions reached a new high, producing 32.5 gigatons [2]. This further emphasizes the need for the development of methods that are renewable as these methods generally have a near-zero net carbon emissions cycle. This is because the $\mathrm{CO}_{2}$ that is produced during the combustion of the biochar and biocrude will then be consumed by plants to grow and produce the biomass. The biggest hurdle for the production of these renewable fuels is the constant struggle between food and fuel. Many of the biomass feedstocks used to produce bio-ethanol is also used as a source of food such as maize or sugarcane [3]. This puts a higher demand on these commodities which causes the price to increase as the producer will most likely sell to the consumer that is willing to pay more [3]. Thus, resulting in an increased price of food. Although most increases in the current price of food is mainly attributed to the price of oil, this could become a serious problem as oil reserves decrease and the global energy requirements demand more from renewables [3].

Renewable fuels thus require a feedstock that is abundant, inexpensive and does not compete as a food source in order to be a viable long-term solution. The research focus has thus been shifted towards waste sources such as food processing waste, microalgae, plantation biomass as well as animal manure and municipal waste [4-8]. Spent coffee grounds (SCG) could be one of the solutions as it is produced in large quantities and does not compete as a food source. Global coffee consumption reached 9.51 million tons in 2017 where

most simply discard the SCG to landfill [9]. SCG typically contains between 10-15 wt.\% oil which could be recovered by means of the Soxhlet extraction method [10]. However, this is a low yield method when compared to thermochemical alternatives.

Thermochemical reactions methods are showing promising results and could be an alternative to extractive methods [11-13]. The high water content of SCG makes it uneconomical as a feedstock for pyrolysis as it requires intensive preliminary drying but ideally suited for hydrothermal liquefaction as water is added to the SCG [8]. The water plays an important role as both a solvent and catalyst during the HTL process.

From Figure 1 it can be seen that, as the temperature of the water is increased, the non-polar solubility of the water increases dramatically [14]. This then causes the biomass to hydrolyze into smaller components that dissolve in the water 
phase. These smaller component then undergo re-polymerization reactions to produce the HTL products [13].

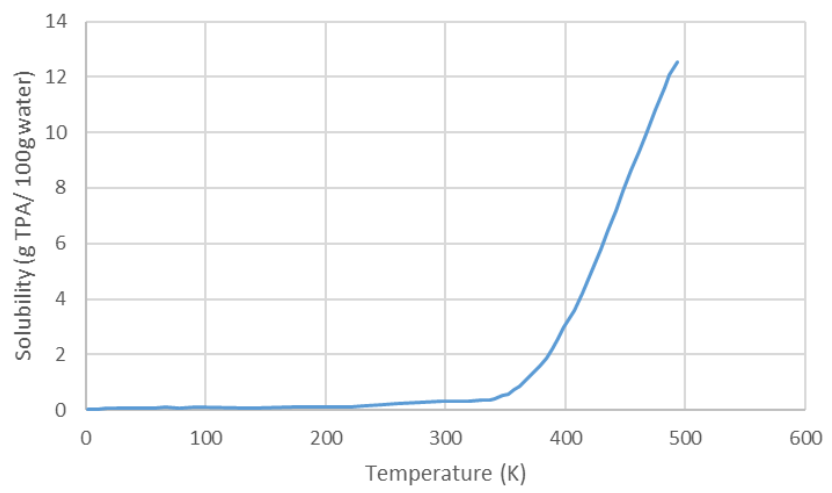

Fig. 1. Non-polar solubility of water at different temperatures, adapted from Savage (2009)

The operating temperature of HTL is also much lower than that of pyrolysis as HTL is usually operated between 250-350 ${ }^{\circ} \mathrm{C}$. SCG has a high cellulose-and-hemicellulose content as well as a low lignin content making it ideal for the production of biocrude by means of HTL [8]. This is because hemicellulose and cellulose hydrolyses at much lower temperatures than lignin which crystalline structure makes is resistant to thermal decomposition [13]. The HTL of SCG is thus worth looking into as a possible source of renewable fuels.

\section{EXPERIMENTAL METHODS}

\section{A. Materials}

The spent coffee grounds were obtained from a local coffee shop near campus. The slurry was prepared using water that had undergone reverse osmosis (RO) as the chlorine in tap water would corrode the stainless steel reactor. The reactor was pressurised by means of nitrogen gas $\left(\mathrm{N}_{2}\right.$ baseline 5.0) cylinders. The biocrude produced in the reactor was separated by dissolving it in acetone whereafter it was filtered by means of a Büchner funnel.

\section{B. Apparatus}

The reactor that was used is a continuous hydrothermal liquefaction pilot plant. The reactor had a $20 \mathrm{~L}$ capacity with feed tanks that could contain approximately 90-100 L of the feed slurry and operate at a maximum flow rate of $150 \mathrm{~L} / \mathrm{h}$. This reactor was designed for a maximum pressure of 99 bar as a pressure relieve valve protected the plant from over-pressure. The reactor temperature was increased by means of the hot oil plant which circulated a heat transfer oil around the plant. The maximum temperature of the hot oil plant was $340^{\circ} \mathrm{C}$ as it is the maximum operating pressure of the heat transfer oil.

The hot oil would flow around the piping of the reactor to transfer the heat. The pre-heater would increase the temperature of the slurry to approximately $130-140^{\circ} \mathrm{C}$ whereafter the temperature of the slurry would be further increased to approximately $185^{\circ} \mathrm{C}$ in the reactor itself. The temperature would then be reduced to approximately $70^{\circ} \mathrm{C}$ in the cooler before it enters the product tanks.

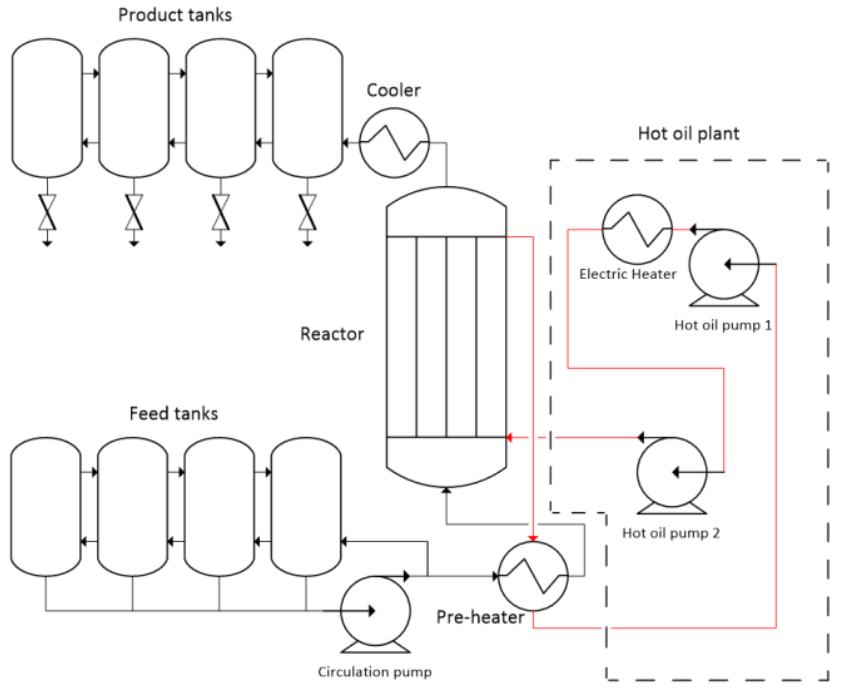

Fig. 2. Process flow diagram of the continuous HTL reactor

Pressure filters were used to separate the aqueous phase from the biochar and biocrude. A Büchner funnel was used to separate the oil-rich acetone from the biochar where after the acetone was recovered by means of a rotary evaporator.

\section{Procedure}

\section{1) Feed preparation}

The SCG was allowed to dry in an oven at $105^{\circ} \mathrm{C}$ whereafter the amount of coffee required to prepare a 3 vol. $\%$ slurry was weighed. The drying step was done to more accurately determine the weight of the SCG as the moisture content from the collected SCG tended to vary slightly. The dried SCG was then mixed with water to prepare a $20 \mathrm{~L}$ slurry and allowed to soak overnight. This allowed any lumps to break apart as well as to mitigate any possible mass transfer limitations between the water and the porous SCG. The soaked SCG slurry was then mixed with more water in the feed tanks to produce a $60 \mathrm{~L}$ slurry with a solids concentration of $3 \mathrm{vol} . \%$.

\section{2) Reactor preparation}

After the slurry was loaded into the feed tanks, the tanks were sealed and the circulation pump switched on. The circulation pump prevented the SCG from settling by continuously circulating the slurry in the feed tanks. To protect the valves of the product tanks, $10 \mathrm{~L}$ of RO water was added to act as a heat buffer. The reactor, feed tanks and product tanks were then pressurized to approximately 90 bar and the hot oil plant heated to $305^{\circ} \mathrm{C}$. The pre-heater was not allowed to heat up during the start-up phase as it would cause the slurry in the feed tanks to heat up. The pre-heater was only opened once the hot oil plant reached $305^{\circ} \mathrm{C}$. Once the temperature of the hot oil plant returned to $305^{\circ} \mathrm{C}$ the flow cut off valve was opened and flow through the reactor was initiated.

\section{3) Reactor operation}

The flow rate of the slurry through the reactor was managed by isolating the feed-and-product tanks from each other and slowly purging the gas in the product tanks. By venting the gas 
from the product tanks, a pressure drop between the feed-and-product tanks was initiated. The flow rate of the slurry was thus controlled by controlling the rate at which the gas in the product tanks was vented. Whilst the gas in the feed tanks was vented at a specific flow rate, the pressure in the feed tanks was kept between $90-95$ bar by adding pressurized nitrogen gas from a cylinder at the same flow rate.

The temperature of the cooler effluent was kept at $70^{\circ} \mathrm{C}$ to prevent the fatty acid based biocrude from solidifying which would result in an obstruction in the cooler.

To protect the circulation pump from running dry a liquid level controller (LLC) attached to a trip switch would shut off the pump once the liquid level in the feed tanks reach the minimum level required to safely operate the pump. The duration of the run would thus be the residence time of the slurry at a set flow past the time when the circulation pump tripped. This was done to ensure that all of the feedstock has passed through the reactor.

Once this time has elapsed the flow through the reactor would be shut off and heaters in the hot oil plant turned off and the plant left to cool down overnight. After the rector has cooled to below $100^{\circ} \mathrm{C}$ the reactor is depressurized and the product collected in $25 \mathrm{~L}$ buckets. The remaining feedstock in the feed tanks was also collected, filtered and then dried to determine the amount of SCG that did not flow through the reactor.

\section{Separation and analysis of the product}

The aqueous phase was separated from the biochar and biocrude by means of a pressure filter as both are in a solid phase at room temperature. The biocrude and biochar filter cake was then transferred into a 5 L Erlenmeyer flask and soaked in 3 $\mathrm{L}$ of acetone. The acetone would dissolve the biocrude in order to separate it from the biochar. A magnetic stirrer was added to agitate the mixture as it was left to soak overnight. The biocrude-rich acetone would then be separated from the biochar by means of a Büchner funnel.

The oven was then set to $105^{\circ} \mathrm{C}$ where the char would be dried overnight. The biocrude was separated from the acetone in a rotary evaporator where the acetone would be recovered and re-used. The yield of these products would be determined by means of the following equation:

Yield $(\%)=\frac{\text { Mass of product }}{\text { Mass of SCG -Mass of SCG in feed tanks }}$

The following qualitative analyses would then be done on the aqueous phase, biocrude and biochar:

TABLE I: ANALYSES PERFORMED ON THE VARIOUS PRODUCTS

\begin{tabular}{|l|c|c|c|}
\hline Analyses & Aqueous phase & Biocrude & Biochar \\
\hline GC-MS & $\bullet$ & $\bullet$ & \\
\hline HHV & & $\bullet$ & $\bullet$ \\
\hline TOC & $\bullet$ & & \\
\hline COD & $\bullet$ & & \\
\hline Total Nitrogen & $\bullet$ & & \\
\hline FTIR & & $\bullet$ & $\bullet$ \\
\hline BET and BJH & & & $\bullet$ \\
\hline
\end{tabular}

The gas in the product tanks were also sampled by means of gas sampling bags that were rated for effective up to $24 \mathrm{~h}$ after the sample was taken.

\section{RESULTS AND DISCUSSION}

\section{1) Fibre analysis of SCG}

Fibre analysis was done to determine the composition of the SCG. The composition of a biomass can significantly impact the biochar and biocrude yields as the different components that make up the biomass will hydrolyse at varying rates and temperatures. Carbohydrates such as hemicellulose and cellulose will undergo rapid hydrolysis when placed under hydrothermal conditions whereas lignin is highly resistant to thermal decomposition and enzymatic attack due to its strong crystalline structure [13]. According to Toor, et al. [13], 100\% of the hemicellulose and cellulose was converted within 2 minutes at $230^{\circ} \mathrm{C}$ and $280^{\circ} \mathrm{C}$ respectively whereas lignin completely hydrolyses between $350-400^{\circ} \mathrm{C}$.

TABLE II: FIBRE ANALYSIS OF THE SCG

\begin{tabular}{|l|c|}
\hline \multicolumn{1}{|c|}{ Component } & wt.\% \\
\hline Ash & 1.34 \\
\hline Protein & 12.71 \\
\hline Fat (Ether extraction) & 12.86 \\
\hline Carbohydrates & 67.62 \\
\hline Hemicellulose & 34.97 \\
\hline Cellulose & 19.26 \\
\hline Lignin & 10.54 \\
\hline
\end{tabular}

\section{AS CAN BE SEEN IN}

Table II above, the SCG has a very high hemicellulose content compared to other lignocellulosic biomass which have a hemicellulose content ranging from 20.5\%-31.4\% [13]. Although the cellulose content was found to be significantly less than most of the lignocellulosic biomass reported by Toor, et al. [13] the total carbohydrate content in the SCG was still relatively high. This high carbohydrate and moisture content makes SCG a good candidate for HTL.

\section{2) Biomass loading}

The maximum biomass loading the reactor was designed for was 5 vol. \%. However, this is dependent on the type of biomass that is used. The optimal biomass loading for the reactor when using SCG thus had to be determined first. This was determined by loading the reactor with various biomass loadings. The optimal biomass loading was then determined as the highest biomass loading that did not cause any blockages. The maximum biomass loading was then determined to be 3 vol. $\%$ for this reactor when using SCG. This is very low when compared to batch HTL where SCG biomass loadings often exceed $30 \mathrm{wt} \%$ [8]. However, this issue could alleviate itself with an industrial scale plant as the diameter of the piping will be much larger than the $1 / 2$ " pipe size used for this reactor. 


\section{3) Reactor temperature profile}

The temperature at different points in the reactor was recorded to determine the temperature profile of the run. As can be seen in Figure 3, the temperature in the hot oil side decreases initially as the cold feed slurry is introduced. However, the temperature does slowly return and stabilize after 15 minutes.

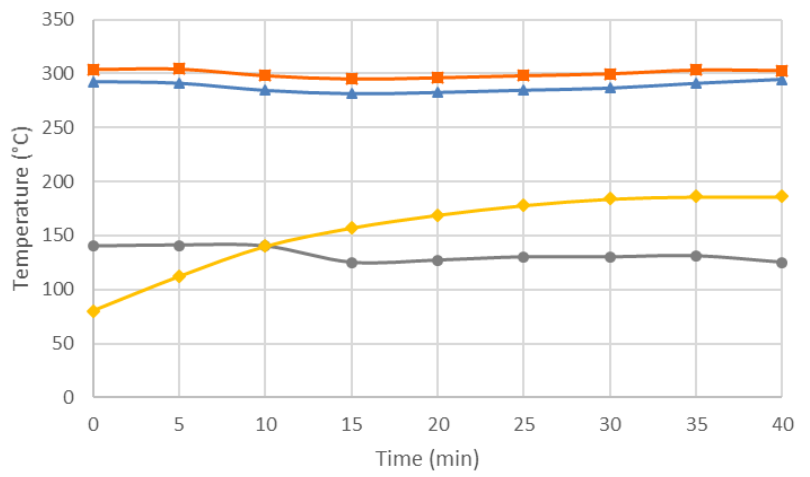

Fig. 3. Temperature profile of the continuous HTL reactor at $120 \mathrm{~L} / \mathrm{h}(\Delta$ Outlet oil Inlet oil $\diamond$ Reactor outlet $\bullet$ Pre-heater outlet)

The slow increase in temperature, as well as the significant difference between the reactor temperature and hot oil temperature, is due to the unique flow conditions in the reactor. These conditions are as a result of the nitrogen gas that is used to pressurise the reactor as well as the relatively slow flow rate. These specific conditions in the reactor causes a gas boundary layer to form between the wall of the reactor and the slurry that flows through the reactor. This boundary layer has a very poor heat transfer rate which causes the large difference in temperature between the reactor and the hot oil.

\section{4) Yields obtained and the effect of residence time thereon}

The yields obtained in this study indicated that the temperature inside the reactor was not the most important factor for the reactor that was used. From the temperature curves, we can see that the temperature did not change significantly between the different runs. However, as can be seen in Table 2 the yield increased as the residence time decreased where the highest yield for both the biochar and biocrude was at $120 \mathrm{~L} / \mathrm{h}$ when using SCG.

TABLE III: BIOCHAR AND BIOCRUDE YIELD AT DIFFERENT RESIDENCE TIMES

\begin{tabular}{|c|c|c|c|c|}
\hline & \multicolumn{2}{|c|}{ Yield (g/kg SCG) } & \multicolumn{2}{c|}{ Yield (wt.\%) } \\
\hline $\begin{array}{c}\text { Residence } \\
\text { time (min) }\end{array}$ & Biochar & Biocrude & Biochar & Biocrude \\
\hline 10 & 152 & 285 & 15.2 & 28.5 \\
\hline 15 & 95 & 242 & 9.5 & 24.2 \\
\hline 20 & 102 & 197 & 10.2 & $19 . .7$ \\
\hline
\end{tabular}

Yang, et al. [8] reported that an increase in residence time does not significantly affect the biochar yield in a batch reactor. The lower biochar yields at the longer residence time does fall within the experimental error and was thus not significantly affected by the change in residence time.

However, the lower biocrude yields at the increased residence time also follow the same trend reported by Yang, et al. [8]. The increased residence time caused the biocrude yields to decrease as the biocrude would then decompose into smaller and lighter components as well as gasses. The optimal residence time for the continuous HTL of SCG was also found to be 10 minutes which also coincides with what was reported by Yang, et al. [8]. This could be due to the relatively short reaction times of the decomposition and hydrolysis reactions that occur during the HTL of a biomass [8]. This improves the economic viability of continuous HTL as the lower residence time with allow for either a much smaller reactor volume or a significantly higher production rate whilst improving the biochar and biocrude yields.

Overall the biochar and biocrude yields were very positive at a maximum of $28.5 \mathrm{wt} . \%$ and $17.7 \mathrm{wt} . \%$ for the biocrude and biochar, respectively. When compared to other continuous HTL reactors, yields were similar to that obtained by Jazrawi, et al. [5], He, et al. [15] and Pedersen, et al. [16].

\section{5) Higher heating value (HHV)}

The HHV of the biochar indicated a slight increase as the residence time was increased. However, it is not significant enough to validate the trend as it falls within the experimental error. We can thus assume that the HHV remained relatively constant and was not significantly affected by the change in residence time. The highest calorific value obtained was 31.1 $\mathrm{MJ} / \mathrm{kg}$ at 20 minutes. This is significantly higher than most of the coal that is mined in South Africa which typically have a $\mathrm{HHV}$ in the range of 20-26 MJ/kg [17]. The biochar also had a significantly higher HHV than that of lignite at $25 \mathrm{MJ} / \mathrm{kg}$ [18].

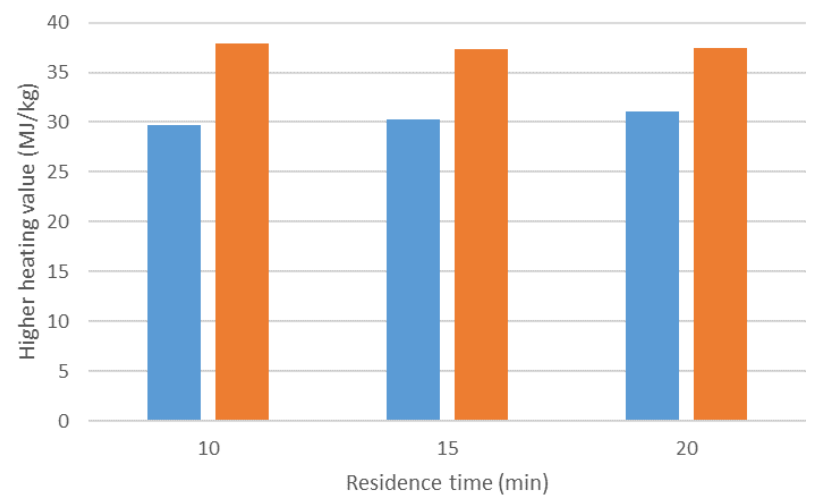

Fig. 4. HHV of the biochar and biocrude ( $\square$ Biochar $\square$ Biocrude)

The biocrude also had a very high HHV however, the HHV of the biocrude was not significantly affected by the change in residence time as the difference between the highest and lowest $\mathrm{HHV}$ was merely $0.5 \mathrm{MJ} / \mathrm{kg}$. The highest calorific value was $37.9 \mathrm{MJ} / \mathrm{kg}$ and was produced at a residence time of $10 \mathrm{~min}$. This is also beneficial towards the economic viability of continuous HTL as a shorter residence time and thus increased flow rate will not affect the quality of the biochar and biocrude product. 
The continuous HTL of SCG produced a biocrude with a higher HHV than the other biocrudes that were produced in a continuous HTL reactor from different strands of microalgae, aspen wood as well as manures and sewage sludge $[5,15,16$, $19,20]$. The HHV of the continuous HTL of SCG is much higher than that of the batch HTL when using SCG where the $\mathrm{HHV}$ was $31 \mathrm{MJ} / \mathrm{kg}$.

Although the energy content of the biocrude is very high it would need to be upgraded as conventional petroleum crude oil has an HHV of 45-46 MJ/kg [21]. This could be accomplished by means hydrotreatment which uses a sulphur activated catalyst in a high-pressure hydrogen atmosphere to deoxygenate the biocrude and would significantly improve the HHV of the biocrude [5].

There was a significant increase in the HHV from SCG to the biocrude and biochar. The HHV of SCG was $22.6 \mathrm{MJ} / \mathrm{kg}$ and after the HTL thereof the energy density was increased by $48.1 \%$ and $63.1 \%$ for the biochar and biocrude respectively.

\section{6) $G C-M S$}

From the GC-MS results in Table 3, we can see that the biocrude mainly consists of $\mathrm{C}_{16}$ and $\mathrm{C}_{18}$ fatty acids which make up about $90 \%$ thereof. n-Hexadecanoic acid $\left(\mathrm{C}_{16} \mathrm{H}_{32} \mathrm{O}_{2}\right)$ is the most common component as it comprises $40.37 \%$ of the biocrude mass. The rest of the biocrude is then made up by octadecanoic acid as well as isomers thereof.

TABLE IV: GC-MS ANALYSIS OF THE BIOCRUDE PRODUCED AT A RESIDENCE TIME OF 10 MIN

\begin{tabular}{|l|c|c|}
\hline \multicolumn{1}{|c|}{ Component } & $\begin{array}{c}\text { Retention } \\
\text { time (min) }\end{array}$ & Area (\%) \\
\hline n-Hexadecanoic acid & 35.001 & 40.41 \\
\hline 9,12-Octadecanoic acid (Z, Z) & 38.607 & 28.33 \\
\hline Octadecanoic acid (Stearic acid) & 39.415 & 7.58 \\
\hline $\begin{array}{l}\text { 9,12-Octadecanoic } \\
\text { acid-2,3-dihydroxypropyl ester }\end{array}$ & 55.636 & 6.03 \\
\hline 9-Octadecanoic acid (Oleic acid) & 38.750 & 4.34 \\
\hline
\end{tabular}

According to Yang, et al. [8] the fatty acids are produced from the decomposition and re-polymerization if the lipids in the SCG. The biocrude produced from SCG in the continuous HTL reactor is very similar to the biocrude that was produced during the batch HTL of SCG [8]. However, slightly less n-hexadecanoic acid, 9,12-octadecanoic acid $(\mathrm{Z}, \mathrm{Z})$ and stearic acid was produced. This could be due to the lower temperatures that the continuous HTL operated at as less cracking reactions results in less of the lighter components in the biocrude [8].

\section{7) $F T-I R$}

Fourier-transform infrared spectroscopy (FT-IR) analyses were performed on the SCG, biocrude and biochar to determine the composition thereof. The absorbance of certain wavelengths will indicate the presence of certain functional groups. A low transmittance percentage indicates that a significant quantity of the functional group is present as more of the specific wavelength could be absorbed.

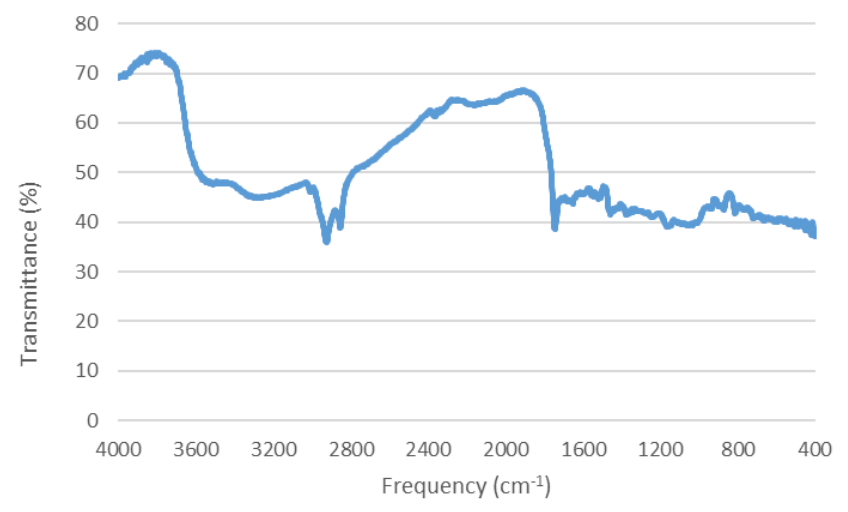

Fig. 5. FT-IR analysis of the SCG

From Fig. 5 we can see that the $3400 \mathrm{~cm}^{-1}$ wavelength was strongly absorbed by the SCG which indicated a high protein and carbohydrate content in the biomass [8]. A much weaker absorbance of this wavelength suggests that the proteins and carbohydrates were successfully decomposed in the continuous HTL reactor.

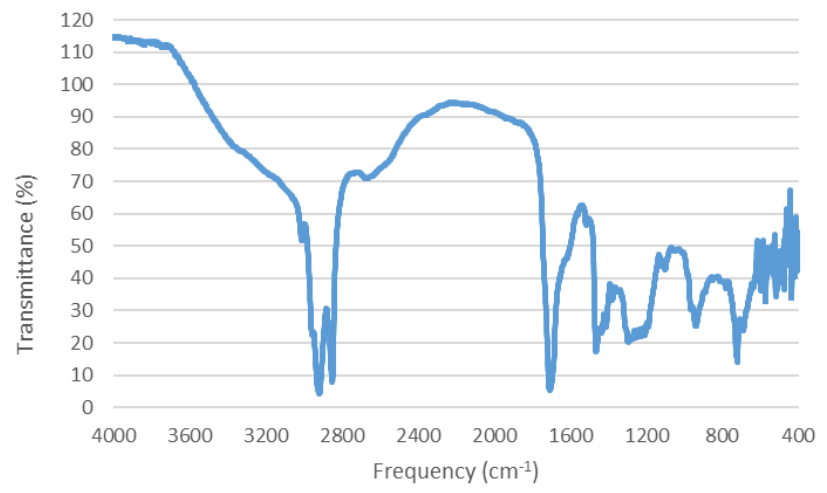

Fig. 6. FT-IR analysis of the biocrude produced at a residence time of $10 \mathrm{~min}$

In the FT-IR analysis on the biocrude shown in Fig. 6, it can be seen that the frequency between $2700-3000 \mathrm{~cm}^{-1}$ was absorbed by the $\mathrm{C}-\mathrm{H}$ bond of the aliphatic functional groups. The strong absorbance in this range is due to the high alkyl content in the biocrude [8]. A strong absorbance is also seen in the FTIR analysis of the biochar in Fig. 7. When compared to the FT-IR results of SCG, the biocrude and biochar indicated a significant increase in the absorbance in this range indicates more long chain alkanes were produced during the HTL of SCG.

The wavelengths between $1650-1750 \mathrm{~cm}^{-1}$ was strongly absorbed by the biocrude which indicated the production of $\mathrm{C}=\mathrm{O}$ from the carboxylic acids and ester groups as the SCG had a much weaker absorbance [8]. This corresponds with the GC-MS as it confirms the presence of the $\mathrm{C}_{16}-\mathrm{C}_{18}$ fatty acids in the biocrude. 


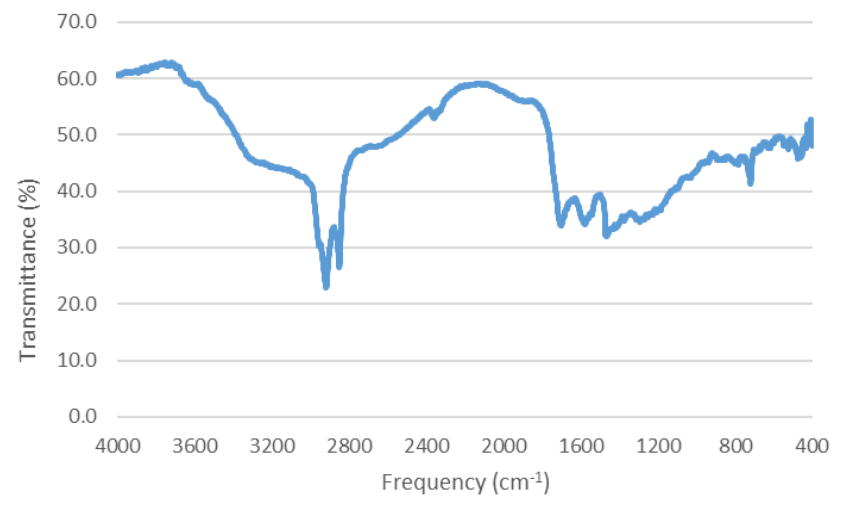

Fig. 7. FT-IR analysis of the biochar produced at a residence time of $10 \mathrm{~min}$

An increase in the absorption in the range of $1500-1600 \mathrm{~cm}^{-1}$ is attributed to a decrease in the lignin content as lignin is hydrolysed into phenolic monomers. The increased The absorption of the $1350-1470 \mathrm{~cm}^{-1}$ range is attributed to the $\mathrm{C}-\mathrm{H}$ bending [8]. The $\mathrm{C}-\mathrm{N}$ bonds that can be found in amine groups was detected by the absorption of the $1050-1350 \mathrm{~cm}^{-1}$ range. Absorbance of the $1050 \mathrm{~cm}^{-1}$ wavelength was due to the $\mathrm{C}-\mathrm{O}$ bonds whereas the absorbance in the $670-870 \mathrm{~cm}^{-1}$ indicated the presence of phenolic rings. The continuous HTL of SCG produced a biochar and biocrude product that contained a range of different chemicals

\section{8) Proximate analysis}

From Table $\mathrm{V}$ we can see that the biocrude had a high moisture content when compared to the biochar. As the biocrude mostly consists of fatty acids, a high volatile content was expected as most of the fatty acids have a boiling point that is lower than $360^{\circ} \mathrm{C}$ [22].

TABLE V: PROXIMATE ANALYSIS ON THE BIOCRUDE AND BIOCHAR PRODUCED AT DIFFERENT RESIDENCE TIMES

\begin{tabular}{|c|c|c|c|c|}
\hline & \multicolumn{4}{|c|}{ Composition (wt.\%) } \\
\hline $\begin{array}{c}\text { Residence } \\
\text { time (min) }\end{array}$ & Moisture & Volatiles & $\begin{array}{c}\text { Fixed } \\
\text { Carbon }\end{array}$ & Ash \\
\hline Biocrude & & & & \\
\hline 10 & 12.2 & 86.6 & 0.7 & 0.5 \\
\hline Biochar & & & & \\
\hline 10 & 1.7 & 44.5 & 50.2 & 3.6 \\
\hline
\end{tabular}

From Table $\mathrm{V}$ it can be seen that the biochar has a very high fixed carbon content. This is beneficial as the higher fixed carbon content causes the combustion temperature to increase [18]. This allows the biochar to be mixed with coal as a large difference in volatile matter content could result in different combustion regions [18]. The biochar produced in this study was similar to the lignite, that was used in a study performed by Liu, et al. [18], in terms of volatiles and fixed carbon content. The volatiles in the biochar was slightly lower however, the lignite had almost $10 \mathrm{wt} . \%$ lower fixed carbon content [18]. The ash content of the biochar was significantly higher than that of lignite.

\section{9) BET and BJH analysis of the biochar}

The Brunauer-Emmett-Teller (BET) and Barett-Joyner-Halenda (BJH) analyses characterise the total surface area and average pore size of the biochar. This gives an indication of the adsorption properties for use as a catalyst base or for water purification.

\section{TABLE VI: BET ANALYSIS ON THE BIOCHAR PRODUCED AT} A RESIDENCE TIME OF 15 MINUTES

\begin{tabular}{|l|c|c|}
\hline \multicolumn{1}{|c|}{ Analysis } & \multicolumn{2}{c|}{ Result } \\
\hline BET surface area & 7.651 & $\mathrm{~m}^{2} / \mathrm{g}$ \\
\hline Langmuir surface area & 24.096 & $\mathrm{~m}^{2} / \mathrm{g}$ \\
\hline $\begin{array}{l}\text { BJH Adsorption cumulative surface } \\
\text { area of pores }\end{array}$ & 16.746 & $\mathrm{~m}^{2} / \mathrm{g}$ \\
\hline $\begin{array}{l}\text { BJH Desorption cumulative surface } \\
\text { area of pores }\end{array}$ & 19.751 & $\mathrm{~m}^{2} / \mathrm{g}$ \\
\hline $\begin{array}{l}\text { BJH Adsorption cumulative volume } \\
\text { of pores }\end{array}$ & 0.154 & $\mathrm{~cm}^{3} / \mathrm{g}$ \\
\hline $\begin{array}{l}\text { BJH Desorption cumulative volume of } \\
\text { pores }\end{array}$ & 0.155 & $\mathrm{~cm}^{3} / \mathrm{g}$ \\
\hline Median pore width & 13.280 & $\mathrm{~nm}$ \\
\hline
\end{tabular}

The residence time did not have a significant effect on the adsorption properties of the biochar as the results were very similar. The BET surface area results of the biochar was very low when compared to other biochars produced by means of hydrothermal carbonisation (HTC) [23, 24]. However, the BET surface area is very low when compared to the biochars that are produced by means of pyrolysis [25]. These biochars typically have a BET surface area between $300-600 \mathrm{~m}^{2} / \mathrm{g}$. This makes the HTL produced biochar a poor option for adsorption purposes. The poor adsorption properties in this study could also be due to the presence of biocrude in the biochar as it could occupy the spaces therein. Thus lowering the surface area and pore volume of the biochar. The pore volume and median pore diameter was slightly higher than HTC biochars and similar to that of biochars produced by means of pyrolysis [25]

\section{0) Gas analysis}

Due to the nature of the reactor compositional analysis of the gas phase was difficult. As the both the product and feed tanks are pressurised with high-pressure $\mathrm{N}_{2}$ cylinders, any gas phase products that are produced in the reactor becomes very diluted. Using a peristaltic pump to increase the pressure would solve this issue and allow for more accurate and representative results.

The gas samples were collected in pre-vacuumed gas sampling bags at different intervals of the run. These intervals were spaced evenly throughout the run to determine how the gas phase composition reacted during the run and how the different residence times/flow rates affect the production and composition thereof. 
TABLE VIII: GC ANALYSIS OF THE GAS PHASE PRODUCED AT A RESIDENCE TIME OF 10 MIN

\begin{tabular}{|l|c|c|c|c|}
\hline & \multicolumn{4}{|c|}{ Area (\%) } \\
\hline \multicolumn{1}{|c|}{ Component } & $\begin{array}{c}\text { Sample 1 } \\
(10 \mathrm{~min})\end{array}$ & $\begin{array}{c}\text { Sample 2 } \\
(20 \mathrm{~min})\end{array}$ & $\begin{array}{c}\text { Sample 3 } \\
(30 \mathrm{~min})\end{array}$ & $\begin{array}{c}\text { Sample 4 } \\
(40 \mathrm{~min})\end{array}$ \\
\hline \multicolumn{1}{|c|}{ FID } & & & & \\
\hline Methane & 0.000 & 0.004 & 0.004 & 0.002 \\
\hline Carbon Monoxide & 0.006 & 0.026 & 0.022 & 0.008 \\
\hline Carbon Dioxide & 0.041 & 0.127 & 0.124 & 0.07 \\
\hline Ethylene & 0.000 & 0.002 & 0.002 & 0.001 \\
\hline Ethane & 0.000 & 0.000 & 0.000 & 0.000 \\
\hline Propane & 0.004 & 0.002 & 0.001 & 0.001 \\
\hline \multicolumn{1}{|c|}{ TCD } & & & & \\
\hline Hydrogen & 0.002 & 0.011 & 0.015 & 0.006 \\
\hline Oxygen & 0.861 & 0.763 & 0.934 & 0.935 \\
\hline Carbon Dioxide & 0.216 & 0.978 & 1.070 & 0.590 \\
\hline Nitrogen & 90.622 & 96.653 & 97.977 & 99.716 \\
\hline \multicolumn{4}{|c|}{} \\
\hline
\end{tabular}

From Table above we can see that the three main components in the gas phase is $\mathrm{N}_{2}, \mathrm{CO}$ and $\mathrm{CO}_{2}$. The formation of $\mathrm{CO}$ and $\mathrm{CO}_{2}$ is indicative of the decarboxylation and decarbonylation that occur during the HTL of biomass as these reactions remove the oxygen in the biomass. Very small amounts of methane, ethylene, propane and hydrogen was detected however, this is outside the detection limit of the thermal conductivity detector (TCD) and flame ionizing detector (FID). Although an FID detector coupled with a methanizer, the GC analyses of the gas phase can only be used as a qualitative representation of the gas phase.

\section{CONCLUSION}

The aim of this study was to determine whether SCG could successfully be used as a feedstock in a continuous HTL reactor. SCG was successfully converted from a low-value waste to the biocrude and biochar products in a continuous HTL pilot plant. The biochar and biocrude yield was similar to that found in literature. However, the products were found to be of a significantly higher quality than the other lignocellulosic-and-algae based feedstocks. The biochar and biocrude that was produced in the continuous HTL pilot plant was very similar in composition and quality to the batch produced biochar and biocrude reported by Yang, et al. [8].

The residence time did not seem to have a significant effect on the quality of the products but did have a significant impact on the yields thereof. The lower residence time improved the yield of the biocrude and biochar products as the higher flow rate significantly decreased the rate of fouling in the reactor. The same can be said for the aqueous phase as the change in residence time did not seem to have a significant effect on the qualitative properties thereof.

\section{ACKNOWLEDGMENT}

The authors would like to acknowledge the National Research Foundation of South Africa for their financial support of this project. Any opinion, finding and conclusion or recommendation expressed in this material is that of the authors and the NRF does not accept any liability in this regard.

\section{REFERENCES}

[1] U.S Energy information administration, "International energy outlook," 2016, Available: https://www.eia.gov/outlooks/ieo/pdf/0484(2016).pdf, Accessed on: 10 June 2016.

[2] N. Chestney. (2018, 2 August 2018). Global carbon emissions hit record high in $2017 . \quad$ Available: https://www.reuters.com/article/us-energy-carbon-iea/global-carbon-emi ssions-hit-record-high-in-2017-idUSKBN1GY0RB

[3] Z. Zhang, L. Lohr, C. Escalante, and M. Wetzstein, "Food versus fuel: What do prices tell us?," Energy Policy, vol. 38, no. 1, pp. 445-451, 2010/01/01/ 2010.

[4] N. D. Berge, K. S. Ro, J. Mao, J. R. Flora, M. A. Chappell, and S. Bae, "Hydrothermal carbonization of municipal waste streams," Environmental science \& technology, vol. 45, no. 13, pp. 5696-5703, 2011. https://doi.org/10.1021/es2004528

[5] C. Jazrawi, P. Biller, A. B. Ross, A. Montoya, T. Maschmeyer, and B. S. Haynes, "Pilot plant testing of continuous hydrothermal liquefaction of microalgae," Algal Research, vol. 2, no. 3, pp. 268-277, 2013. https://doi.org/10.1016/j.algal.2013.04.006

[6] M. Sugano, H. Takagi, K. Hirano, and K. Mashimo, "Hydrothermal liquefaction of plantation biomass with two kinds of wastewater from paper industry," Journal of Materials Science, vol. 43, no. 7, pp. 2476-2486, 2008.

https://doi.org/10.1007/s10853-007-2106-8

[7] C. S. Theegala and J. S. Midgett, "Hydrothermal liquefaction of separated dairy manure for production of bio-oils with simultaneous waste treatment," Bioresource Technology, vol. 107, pp. 456-463, 2012/03/01/ 2012.

[8] L. Yang, L. Nazari, Z. Yuan, K. Corscadden, and C. C. Xu, "Hydrothermal liquefaction of spent coffee grounds in water medium for bio-oil production," Biomass and Bioenergy, vol. 86, pp. 191-198, 2016. https://doi.org/10.1016/j.biombioe.2016.02.005

[9] International coffee organization. (2018, 2 August 2018). Total production by all exporting countries. Available: http://www.ico.org/historical/1990\%20onwards/PDF/1a-total-productio n.pdf

[10] N. Kondamudi, S. K. Mohapatra, and M. Misra, "Spent Coffee Grounds as a Versatile Source of Green Energy," Journal of Agricultural and Food Chemistry, vol. 56, no. 24, pp. 11757-11760, 2008/12/24 2008.

[11] T. Damartzis and A. Zabaniotou, "Thermochemical conversion of biomass to second generation biofuels through integrated process design-A review," Renewable and Sustainable Energy Reviews, vol. 15, no. 1, pp. 366-378, 2011. https://doi.org/10.1016/j.rser.2010.08.003

[12] H. Goyal, D. Seal, and R. Saxena, "Bio-fuels from thermochemical conversion of renewable resources: a review," Renewable and sustainable energy reviews, vol. 12, no. 2, pp. 504-517, 2008. https://doi.org/10.1016/j.rser.2006.07.014

[13] S. S. Toor, L. Rosendahl, and A. Rudolf, "Hydrothermal liquefaction of biomass: a review of subcritical water technologies," Energy, vol. 36, no. 5, pp. 2328-2342, 2011. https://doi.org/10.1016/j.energy.2011.03.013

[14] P. E. Savage, "A perspective on catalysis in sub- and supercritical water," The Journal of Supercritical Fluids, vol. 47, no. 3, pp. 407-414, 2009/01/01/ 2009.

[15] Y. He et al., "Continuous hydrothermal liquefaction of macroalgae in the presence of organic co-solvents," Algal Research, vol. 17, pp. 185-195, 2016. https://doi.org/10.1016/j.algal.2016.05.010

[16] T. H. Pedersen et al., "Continuous hydrothermal co-liquefaction of aspen wood and glycerol with water phase recirculation," Applied Energy, vol. 162, pp. 1034-1041, 2016. https://doi.org/10.1016/j.apenergy.2015.10.165 
[17] L. Jeffrey, "Characterization of the coal resources of South Africa," Journal of the Southern African Institute of Mining and Metallurgy, vol. 105, no. 2, pp. 95-102, 2005.

[18] Z. Liu, A. Quek, S. Kent Hoekman, and R. Balasubramanian, "Production of solid biochar fuel from waste biomass by hydrothermal carbonization," Fuel, vol. 103, pp. 943-949, 2013/01/01/ 2013.

[19] D. C. Elliott, P. Biller, A. B. Ross, A. J. Schmidt, and S. B. Jones, "Hydrothermal liquefaction of biomass: developments from batch to continuous process," Bioresource technology, vol. 178, pp. 147-156, 2015. https://doi.org/10.1016/j.biortech.2014.09.132

[20] K. Prapaiwatcharapan, S. Sunphorka, P. Kuchonthara, K. Kangvansaichol, and N. Hinchiranan, "Single-and two-step hydrothermal liquefaction of microalgae in a semi-continuous reactor: effect of the operating parameters," Bioresource technology, vol. 191, pp. 426-432, 2015. https://doi.org/10.1016/j.biortech.2015.04.027

[21] I. Hore-Lacy, Nuclear Energy in the 21st Century: World Nuclear University Press. Elsevier, 2010.

[22] G. Knothe, "Dependence of biodiesel fuel properties on the structure of fatty acid alkyl esters," Fuel Processing Technology, vol. 86, no. 10, pp. 1059-1070, 2005/06/25/ 2005.

[23] A. Fuertes et al., "Chemical and structural properties of carbonaceous products obtained by pyrolysis and hydrothermal carbonisation of corn stover," Soil Research, vol. 48, no. 7, pp. 618-626, 2010. https://doi.org/10.1071/SR10010

[24] N. U. Saqib, S. Baroutian, and A. K. Sarmah, "Physicochemical, structural and combustion characterization of food waste hydrochar obtained by hydrothermal carbonization," Bioresource Technology, vol. 266, pp. 357-363, 2018/10/01/ 2018.

[25] J. S. Cha et al., "Production and utilization of biochar: a review," Journal of Industrial and Engineering Chemistry, vol. 40, pp. 1-15, 2016. https://doi.org/10.1016/j.jiec.2016.06.002

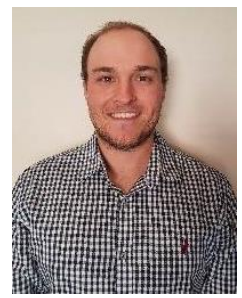

Julius von Wielligh was born on 17 June 1994 and matriculated in 2012 at Barberton High school. He was accepted to study engineering at the North-West University (NWU) Potchefstroom campus and was a first year in 2013. He did research in the settling of coal fines at different conditions as vacation work at the NWU Potchefstroom campus. He is currently busy with his masters degree in chemical engineering which focusses on producing renewable fuels from spent coffee grounds.

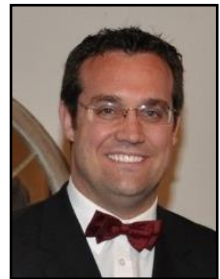

C.J. Schabort started his career as a process engineer at SASOL and joined the North-West University (NWU) in 2009 as a lecturer. He also became a member of the Biofuels Research group within the Faculty of Engineering. He holds both a bachelor's and a master's degree in chemical engineering, both obtained from the NWU. He is currently pursuing a $\mathrm{PhD}$ in chemical engineering in the field of renewable diesel produced from bio-oil derived from the HTL process using spent coffee grounds as feedstock. 